\section{Judgments of body and object verticality in the presence of discordant visual information}

\author{
JAN MOTTRAM and G. SINGER \\ Macquarie University, North Ryde, New South Wales 2113, Australia
}

In two experiments designed to assess the degree of visual dominance with varying amounts of nonvisual information, Ss secured in a lateral-tilt chair were presented with the same two tasks in each experiment, a judgment of the verticality of the body and a judgment of the verticality of an object (a bar). Sensory discordance was produced in these tasks between vision and other modalities by means of double Dove prisms in front of the right eye. In the first experiment $(78 \mathrm{Ss}), \mathrm{S}$, in six different experimental conditions, judged when his body or a bar felt upright in the presence of the transformed visual image of his body, seen in a mirror, or the bar viewed directly. It was found that when judging the verticality of the body, "visual capture" extended to only some of the transformations employed and was quantitatively less than when judging the verticality of the bar, where "visual capture" extended to all transformations used. In a second experiment (39 Ss), S, in three different experimental conditions, was asked to set his body or the bar until it looked upright. It was found that with these "visual" instructions Ss could perform both tasks with reasonable accuracy, thus indicating that in the first experiment, the visual information available to the $S$ had been adequate. From these two experiments, it was concluded that in the body-tilt task "visual capture" was less consistent than it was in the kinesthetic task.

Conflict between visual and nonvisual systems of the body can be produced by optical transformation of the visual input. Many workers (e.g., Held \& Freedman, 1963; Over, 1966; Rock \& Harris, 1967; Day \& Singer, 1967) have used this technique in situations where the relevant relationship is between a restricted number of modalities, namely, vision and kinesthesis proprioception. Over (1966) found that with vision transformed by means of Dove prisms, the S's judgment of the horizontality of a bar depended on the amount of discordance between vision and proprioception.

Since all studies to date show that the optical array determines the response, i.e., vision is dominant, this experiment was designed to assess the degree of dominance as a function of varying amounts of nonvisual information. The two tasks were judgments of body orientation and judgments of the verticality of an object while the object (a bar) was in contact with S's hand. In the body-orientation situation the relevant relationship is between vision and a whole complex of nonvisua: cues. A conflict between vision and the nonvisual body systems could be introduced by allowing $S$ to view his head and shoulders in a mirror through double Dove prisms while he was being returned from a position of lateral tilt. Here vision is opposed to the combined weight of information from vestibular, proprioceptive, and

The three-component apparatus was a modification of the one used by Hazlewood \& Singer (1969) and consisted of a lateral-tilt chair, a monocular optical system, and a kinesthetic component, shown in Fig. 1. In this apparatus $S$ could be tilted laterally in a seated position, while monocularly viewing his image in a mirsor through double Dove prisms, or could be seated in an upright position, while judging the orientation of a bar both visually (through the prisms) and kinesthetically (by moving his hand along the edge of the bar).

The lateral-tilt chair was manually operated by $\mathrm{E}$ and was capable of $360-\mathrm{deg}$ rotation. The fittings included a biteboard for head stabilization, padded shoulder supports, and thigh, knee, and foot straps. A monocular optical system, consisting of a pair of Dove prisms for the right eye, was fitted to the chair by means of an adjustable mounting to permit each $\mathrm{S}$ to view his head and shoulders in a mirror positioned in front of the chair and so as to provide no other cues to orientation. By adjusting the angular orientation of one prism relative to the other, the retinal projection of S's image or of a physically vertical bar could be slanted up to 90 deg to the right or left.

The kinesthetic component consisted of a wooden bar mounted on an aluminium rod attached to a wood frame. The bar could be positioned in front of the upright $S$ so that its orientation could be judged visually through the monocular optical system or kinesthetically by motion of the right hand along its edge. A rotary control operated by S's left hand provided a means of varying the bar's orientation.

\section{Subjects}

There were six groups of $13 \mathrm{Ss}$ ( 7 males and 6 females in each group) drawn from Sydney University and Sydney Teachers' College students. Ss were allocated to treatment conditions sequentially.

\section{Procedure}

Each $S$ was presented with two tasks, a judgment of the verticality of the body (BOJ task) and a judgment of the verticality of the bar (KJ task). The order of presentation of the tasks was alternated across Ss. In each of the tasks a two-phase procedure of pretest and test was used. The pretest consisted of a judgment of verticality (of the body or the bar) with vision occluded. With the exception of Treatment Condition 6 , the test phase required a judgment of verticality with vision available.

Six treatment conditions were employed, all groups receiving identical pretests with occluded vision.

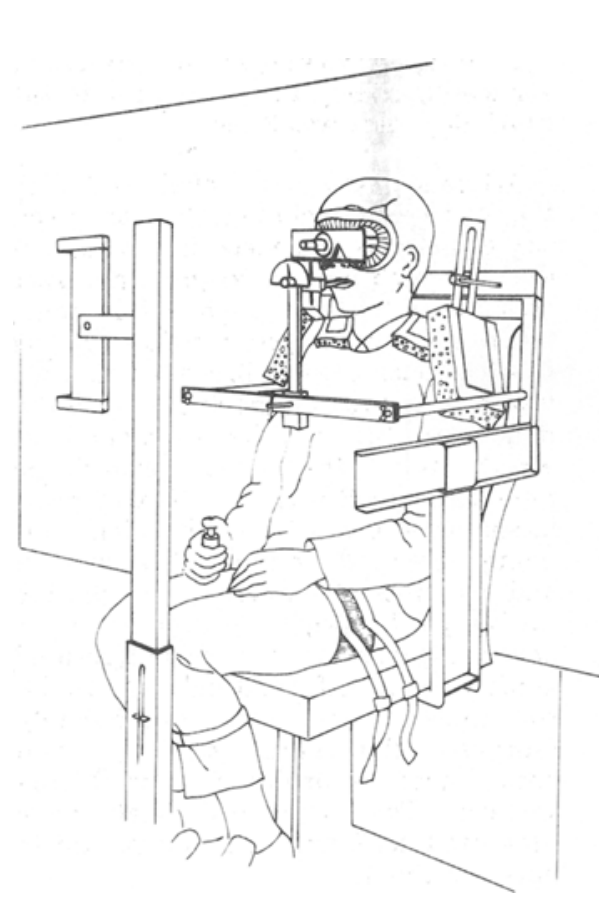

Figure 1 
Table 1

Experiment 1: Body Orientation Judgment Task (BOJ Task). Test Phase

\begin{tabular}{lcrr}
\multicolumn{1}{c}{ Condition } & $\begin{array}{c}\text { Sample } \\
\text { Neans }\end{array}$ & $\begin{array}{c}\text { Sample } \\
\text { Variances }\end{array}$ & $\begin{array}{c}\text { Population } \\
\text { Means in } \\
\text { Terms of } \sigma_{\epsilon}\end{array}$ \\
\hline 1 Transformation 15 Deg R & -5.77 & 24.32 & -1.10 \\
2 Transformation 15 Deg L & 7.23 & 29.07 & 1.37 \\
3 Transformation 30 Deg R & 0.23 & 25.36 & 0.04 \\
4 Transformation 30 Deg L & $\mathbf{3 . 2 3}$ & $\mathbf{1 1 . 9 0}$ & 0.61 \\
5 No transformation (normal vision) & $\mathbf{2 . 4 2}$ & $\mathbf{5 . 4 9}$ & $\mathbf{0 . 4 6}$ \\
6 No vision & $\mathbf{5 . 8 5}$ & $\mathbf{5 . 3 9}$ & 1.11 \\
\hline
\end{tabular}

Table 2

Experiment 1: Kinesthetic Judgment Task (KJ Task), Test Phase

\begin{tabular}{lrrr}
\multicolumn{1}{c}{ Condition } & $\begin{array}{c}\text { Sample } \\
\text { Means }\end{array}$ & $\begin{array}{c}\text { Sample } \\
\text { Variances }\end{array}$ & $\begin{array}{c}\text { Population } \\
\text { Means in } \\
\text { Terms of } \sigma_{\epsilon}\end{array}$ \\
\hline 1 Transformation 15 Deg R & -11.88 & 7.13 & -1.07 \\
2 Transformation 15 Deg L & 13.69 & 12.65 & 1.23 \\
3 Transformation 30 Deg R & -11.04 & 13.35 & -0.99 \\
4 Transformation 30 Deg L & 9.19 & 11.81 & 0.83 \\
5 No transformation (normal vision) & 1.31 & 0.65 & 0.12 \\
6 No vision & 1.58 & 12.70 & 0.14 \\
\hline
\end{tabular}

In Treatment Condition 1 , the visual transformation in the test phase was $15 \mathrm{deg}$ rotation to the $\mathrm{Ss}$ ' right; in Condition 2, transformation was $15 \mathrm{deg}$ left; Condition $3,30 \mathrm{deg}$ right; Condition 4,30 deg left. In Condition 5 , Ss looked through the same optical system, but the prisms were not rotated (normal vision), and in Condition 6 , vision was occluded in the test phase (no vision).

Judgment of the Verticality of the Body (BOJ Task)

The starting position used in the BOJ task was 45 deg right body tilt. Speed of return of the chair was constant at $5 \mathrm{deg} / \mathrm{sec}$, while speed of initial tilt was randomly varied over trials for each $S$, ranging from 3 to $7 \mathrm{deg} / \mathrm{sec}$ to prevent $S$ from using "counting" procedures in estimating verticality. Delay at the maximum tilt of $45 \mathrm{deg}$ right was $2 \mathrm{sec}$.

While secured in the chair and with the eyepiece occluded, $S$ was given three pretests (spaced $2 \mathrm{~min}$ apart) during which he had to press a buzzer as soon as he felt upright while being returned from a tilted position. During the test phase, $\mathbf{S}$ was informed that his vision would remain occluded until the maximum tilt had been reached, at which time the cover would be removed and $\mathbf{S}$ was then to watch his image in the mirror as the chair was being returned towards the vertical and to press the buzzer immediately his body felt upright. E then offset the covered prism to the predetermined amount of transformation and tilted $S$ to $45 \mathrm{deg}$ right, then immediately removed the cloth occluder and commenced returning $S$ towards the vertical. Two such test trials were presented to $S$ with a 2 -min period in between them.

\section{Judgment of the Verticality} of the Bar (KJ Task)

The $S$, seated upright in the lateral-tilt chair with the bar in front of him and with the optical system occluded, made three pretest adjustments of the bar to the vertical. With the prisms offset the appropriate amount, the cover was removed from the eyepiece and $S$ made two test judgments, with instructions which emphasized that the bar be moved until it felt upright while both viewing it through the optical system and moving his right hand along its surface. Thus, in a similar way to the BOJ task, Ss in Groups 1-5 could see their hands and the bar, whereas in Group 6 the sight of the bar and hand was occluded. Starting positions of the bar were varied randomly over trials for each $S$, being either 5 or $10 \mathrm{deg}$ to the right or left of the true vertical.

$$
\text { Results }
$$

All measurements were recorded to the nearest degree. Unsigned values indicate a setting to the right of the physical vertical.

Results of the test phase are presented in Tables 1 and 2. The tables show sample means and variances and population means in units of $\sigma_{\epsilon}$, derived from the data by Rodger's direct method (Rodger, 1967). Differences between population means of less than $\pm 1 / 3 \sigma_{\epsilon} \sqrt{\Sigma c_{\mathrm{ij}}{ }^{2}}$ are considered, in the context of this investigation, to be too small to warrant interpretation and can meaningfully be regarded as zero.

\section{DISCUSSION}

The results show that with an increase in nonvisual information the degree of visual dominance is reduced. In the $K J$ task, where visual information was opposed to information from a subsystem of the kinesthetic system, "visual capture" occurred when vision was transformed either 15 or 30 deg right or left. [This is in accordance with Over's findings (1966).] However, in the BOJ task, where vision was opposed to the mass of information from the vestibular. proprioceptive, tactile, and kinesthetic systems, "visual capture" occurred only under some conditions, namely, with smaller transformations in the same direction as the initial body tilt. So the extent of visual capture and also the tolerance to discordance differed in the two tasks.

Results also show that in the BOJ task, judgments of verticality with nontransformed (normal) vision differed from those made when vision was occluded, whereas in the $\mathrm{KJ}$ task, there was no difference in the two conditions. There is no explanation at present for this different pattern of results in the two tasks.

Because of the differential effects of right and left transformations in the BOJ task, which did not occur in the $\mathrm{KJ}$ task, it is necessary to examine the nature of the visual input and its relationship to the vertical meridian of the eye. In the $\mathrm{KJ}$ task, as the bar moved, the orientation of its retinal projection changed with respect to the vertical meridian of the eye. In the BOJ task, the visual input to the retina maintained a constant relationship to the vertical meridian of the eye (apart from slight countertorsion effects). As $S$ moved so did the retinal image of his head and shoulders.

It follows that one possible explanation for the different results in the two tasks might be that $S$ received less information from his retinal image in the BOJ task. This hypothesis was examined in a second experiment.

\section{EXPERIMENT 2}

Apparatus

The same apparatus as in Experiment 1

\section{Subjects}

Three groups of $13 \mathrm{Ss}$ ( 7 male and 6 female in each group) were drawn from the same population as Experiment 1.

\section{Procedure}

In Experiment 1 S's task was to judge when his body or the bar felt upright; thus the emphasis was placed on ignoring visual information and making a judgment in terms of nonvisual information. In Experiment $2 \mathrm{~S}$ was instructed to judge when his body or the bar looked upright, that is, to ignore the nonvisual information and concentrate on the visual information received from the visual image of his body or the bar.

In Conditions 1 and 2 prism transformation was $15 \mathrm{deg}$ to the right or left, and in Condition 3 vision was not transformed (normal vision). 
Table 3

Experiment 2: Body Orientation Judgment Task (BOJ Task), Test Phase

\begin{tabular}{lrrr}
\multicolumn{1}{c}{ Condition } & $\begin{array}{r}\text { Sample } \\
\text { Means }\end{array}$ & $\begin{array}{r}\text { Sample } \\
\text { Variances }\end{array}$ & $\begin{array}{c}\text { Population } \\
\text { Means in } \\
\text { Terms of } \sigma_{\epsilon}\end{array}$ \\
\hline 1 Transformation 15 Deg R & -13.69 & 8.94 & -1.10 \\
2 Transformation 15 Deg L & 15.35 & 25.35 & 1.23 \\
3 No transformation (normal vision) & 1.81 & 7.81 & 0.14 \\
\hline
\end{tabular}

Table 4

Experiment 2: Kinesthetic Judgment Task (KJ Task), Test Phase

\begin{tabular}{lrrr}
\multicolumn{1}{c}{ Condition } & $\begin{array}{c}\text { Sample } \\
\text { Means }\end{array}$ & $\begin{array}{c}\text { Sample } \\
\text { Variances }\end{array}$ & $\begin{array}{c}\text { Population } \\
\text { Means in } \\
\text { Terms of } \sigma_{\epsilon}\end{array}$ \\
\hline 1 Transformation 15 Deg $R$ & -11.38 & 5.67 & -0.91 \\
2 Transformation 15 Deg L & 15.73 & 0.90 & 1.26 \\
3 No transformation (normal vision) & 0.58 & 0.45 & 0.05 \\
\hline
\end{tabular}

$\mathrm{S}$ was again given three pretests with vision occluded; then, in the test phase, $\mathbf{S}$ was asked to either adjust the bar until it looked upright or to indicate, by pressing a buzzer, when his image looked upright while returning from an initial tilt of $45 \mathrm{deg}$ right. There were two test trials with a 2-min interval between them.

Results and Discussion

Results shown in Tables 3 and 4 indicate that when S's visual input is transformed, "visual" judgments are made with accuracy despite the conflicting information provided by the nonvisual systems. This was the case in both the BOJ task and the $\mathrm{KJ}$ task. It is concluded that, while the visual information available to $S$ in these two tasks may be different, there is sufficient information from the visual system in the BOJ task for $\mathrm{S}$ to perform this task with reasonable accuracy. The question remains, however, as to the extent to which Ss utilize this information when the instructions emphasize that $S$ is to judge when his body feels upright, as he was instructed to do in Experiment 1.

\section{CONCLUSIONS}

In the first experiment, it was found that the whole body showed a smaller extent of "visual capture" and less tolerance to discordance when compared with "visual capture" of one limb.

By relating the second experiment to the first, it was found that "visual capture" was less consistent in the BOJ task as variations in the instructions given to $\mathrm{Ss}$ reduced the amount of capture in Experiment 2 relative to that of the first $\mathrm{ex}_{\mathrm{t}}$-riment.

While all the determinants of the effects found in the body-tilt situation with transformed visual input are not known, this study has provided evidence that "visual capture" does occur under some circumstances when vision is opposed to a complex of nonvisual sensory modalities, although these effects are smaller and less consistent than those obtained when the nonvisual cues are confined to a body subsystem

It thus appears that the degree of visual dominance is, at least partially, a function of the amount of nonvisual of items from STS to LTS.
Several investigators (Murdock, 1965; Baddeley, Scott, Drynan, \& Smith, 1969; and Bartz \& Salehi, 1970) have examined the effect of a concurrent task on free recall. Their results all indicate that, like many other variables -age, presentation rate, word frequency, list length, associative structure-concurrent task load affects solely the amount held in long-term store (LTS). Short-term store (STS) is unaffected. In the present study, both delayed and immediate recall conditions are used to separate STS and LTS components fully for all serial positions. The results will also afford a check on some anomalous results (Bartz \& Salehi, 1970).

$$
\text { METHOD }
$$

The Ss were shown 18 lists, each of 12 words. After each word they were shown an addition task at one of three levels of difficulty. The tasks, in order of difficulty, were adding 1,4 , or 7 to a two-digit number. The same addend was used throughout a list. The Ss recalled the list either with or without delay. The experimental paradigm of three levels of difficulty across two recall conditions was replicated three times per $\mathrm{S}$.

* Requests for reprints should be sent to Murray Glanzer, Department of Psy chology. New York University, 707 Broadway, New York, N.Y. 10003.

information provided by other modalities but that this relationship of the interaction of modal systems is of considerable complexity.

\title{
REFERENCES
}

DAY R. H. \& SINGER, G. Sensory adaptation and behavioural compensation with spatially transformed vision and hearing. Psychological Bulletin, 1967, 67 307-322.

HAZLEWOOD, V \& SINGER, G Kinesthetic orientation judgments during lateral head, body and trunk tilt. Perception \& Psychophysics, 1969,5, 141-142.

HELD, R., \& FREEDMAN, S. Plasticity in human sensorimotor control. Science, 1963, 142, 455-462.

OVER, $R$. An experimentally induced conflict between vision and proprioception. British Journal of Psychology, 1966, 57, 335-341.

ROCK, I. \& HARRIS, C. S. Vision and touch. Scientific American, 1967, 216. 96-104.

RODGER, R. S. Type II errors and their decision basis. British Journal of Mathematical \& Statistical Psychology. $1967,20,187-204$

\section{Concurrent task in free recall: Differential effects of LTS and STS*}

\author{
CAROL SILVERSTEIN and MURRAY GLANZER* \\ New York University, New York, N.Y. 10003
}

Ss carried out tasks at one of three levels of difficulty while being presented with free-recall lists. Immediate and delayed recall of the lists were then tested. The results show that difficulty of the concurrent task lowers the output from long-term store (LTS) but does not affect short-term store (STS) at all. The results are consistent with the hypothesis that information load blocks transfer

\section{Materials}

Words were monosyllabic nouns, from the Thorndike \& Lorge (1944) A A frequency lists for the experimental lists and from the A lists for the practice lists and interference task. All words, numbers, and orders of list presentation were independently randomized by computer for each $\mathrm{S}$.

\section{Procedure}

A memory drum rotated every $2 \mathrm{sec}$ to display, alternately, a new word or a new addition task to $S$. The $S$ said the list words, the sums, and the delay words out loud. On no-delay lists a yellow mark after the last addition task signaled the start of recall. On delay lists the last addition task was followed by two lines of three words each, successively, and then the yellow recall signal.

The $\mathrm{S}$ was told to recall only the list words, in any order. He was given $1 \mathrm{~min}$ for recall. Before the 18 main lists were given, the $\mathrm{S}$ had two practice lists, one delay, one no-delay. Recall was written.

\section{Subjects}

The Ss were 42 undergraduate students at New York University who participated as part of a course requirement. 